\title{
LA ASISTENCIA SANITARIA PÚBLICA EN YECLA (MURCIA): 1850-1930
}

\author{
José Soriano Palao \\ Dr. en Medicina y Cirugía. Servicio de Medicina interna. \\ Hospital Virgen del Castillo, Yecla (Murcia)
}

\section{RESUMEN}

En el presente trabajo se recogen los datos disponibles sobre la organización de la asistencia sanitaria pública en la ciudad de Yecla (Murcia) en el período comprendido por la segunda mitad del siglo XIX y las tres primeras décadas del siglo XX. Partiendo del estudio de las Actas Capitulares y de las Juntas de Sanidad fundamentalmente y basándonos en las disposiciones legales de la época, la Ley General de Sanidad de 1855 y la Instrucción General de Sanidad de 1904, se analiza la evolución de la higiene pública, el trabajo de los médicos titulares y las actuaciones de 1a Junta de Sanidad en un período caracterizado por el inicio de la caída de las tasas de mortalidad y que ha venido en denominarse de «transición sanitaria» $\mathrm{o}$ «transición epidemiológica».

\section{SUMMARY}

This work picks up the available data on the organization of the public sanitary attendance in Yecla from the second helf of the XIX century until the first decades of the XX century. This amount of information allows to analyze the evolution of the public hygiene, the work of the regular doctors and the performances of the Council of Sanity during a period characaterized for the decrease of the rate of mortality.

\section{INRODUCCIÓN}

La asistencia sanitaria pública, tal como hoy la conocemos, tiene su origen en un lento proceso desarrollado a lo largo del siglo XIX y principlos del XX, el cual, partiendo de las disposiciones del estado absolutista borbónico sobre salubridad de las poblaciones y sobre epidemias, tiene su punto de llegada en la creación del Seguro Obligatorio de Enfermedad a mediados del presente siglo.

Este proceso presenta dos características fundamentales. En primer lagar, supone un cambio en la concepción originaria de la sanidad pública desde su consideración como instrumento de policía sanitaria, esto es, de prevención de la salud colectiva, hasta la aparición de la asistencia individualizada del enfermo por parte del Estado. 
En segundo lugar, el papel fundamertal que los ayuntamientos y el cuerpo de médicos titulares tuvieron en la organización sanitaria durante todo el período.

En las páginas que siguen trataremos de acercarnos a lo que fue la organización sanitaria de la ciudad de Yecla y a los hombres y mujeres que le dieron soporte, desde mediados de siglo hasta los años previos a la segunda República, siguiendo el hilo conductor de la legislación sanitaria generada en esos años.

\section{ANTECEDENTES: LOS PARTIDOS MÉDICOS}

«Esta villa, entre los privilegios que cuenta en sus archivos (...) el de poder nombrar tres plazas de facultativos de medicina con el sueldo de seiscientos ducados anuales cobrados de propios...»

Así consta, en el acta de la sesión ordinaria del Ayuntamiento de Yecla del 6 de octubre de 1834, la existencia de un privilegio concedido por el rey Felipe V en el año de 1725 .

El supuesto privilegio se había concretado en el reglamento de 14 de mayo de 1746, promulgado por el Consejo de Castilla, el cual regulaba los partidos médicos, en los que la asistencia médica central se organizaba mediante la asociación de todos los vecinos del pueblo, los cuales contrataban a uno o varios médicos y contribuían, entre todos, al pago de sus haberes anuales. El contrato se establecía entre el Ayuntamiento y el facultativo, y se debía someter a una reglamentación adecuada en cuanto a haberes, tiempo de vigencia, obligaciones, formas de pago, etc. ${ }^{1}$

Sin embargo dicho reglamento había caído en desuso a comienzos del siglo XIX, como se reconoce en el acta citada: «... pero como sea expedido por el Rey el Señor D. Felipe en el año de mil setecientos veinte y cinco y no se halla renobado por los demas señores reyes que le han subcedido...». De hecho, la situación a principios de siglo en Yecla no puede ser más precaria. En plena Guerra de la Independencia, Yecla disponía solo de dos médicos ${ }^{2}$ y uno de ellos había anunciado su deseo de abandonar la localidad. En 1809, en el Ayuntamiento se puso de manifiesto que: «si no se procura que haya al menos dos [médicos] y se mueven algunas enfermedades como suele acontecer, peligra mucho la salud pública y teniendo presente [el Ayuntamiento] se halla con facultad del Consejo para nombrar tres de dichos facultativos con el salario de quinientos ducados cada uno repartidos al vecindario, cerrando la conducta y dividiendo el pueblo en cuarteles acordo: se saque del archivo dicha facultad y se

1 Albarracín Teulon, A. (1969), «La asistencia médica rural en la España del siglo XIX», Asclepio, vol. XXI, 35-42.

2 D. Miguel Rubio Ibáñez de Cerbera, que en 1802 ostentaba el cargo de Símdico Personero y de médico titular de la Villa, y D. Antonio Palao Espejo (AHMY, AC 17/8/1802). 
dé cuenta de ella y demás antecedentes que haya, en el Ayuntamiento que se celebrará en el día de mañana...» ${ }^{3}$. La preocupación del Ayuntamiento era lógica si tenemos en cuenta que, unos años antes, en 1802, Yecla, contando con cinco médicos, había sufrido un brote de «...tercianas malignas y calenturas pútridas (...) experimentándose muchas muertes, haviendo dias que sale el viatico quince y mas veces haciendo progresos de día en día la epidemia, no solo amenazando a esta población entera si no es tambien a las confinantes» ${ }^{4}$. Así, en la sesión del día siguiente, 23 de mayo de 1809 , se plantea la cuestión de contratar colectivamente a tres médicos con un sueldo estipulado. Reproducimos el relato de las consideraciones del pleno por el interés que tiene para aproximarnos a la situación de la asistencia médica a principios de siglo: «...enterados de la real facultad para cerrar la conducta de este pueblo poniendo tres médicos con dotación cada uno de quinientos ducados repartidos al vecindario con equidad y proporción ${ }^{5}$ cuya facultad no es dada por tiempo determinado y si absoluta y que aunque habiendo hecho uso de dicha facultad la Villa cerrando la referida conducta, volvió posteriormente a abrirla a solicitud del corto número de diez y siete vecinos que se quejaron de la falta de asistencia de los médicos admitidos y desigualdad o recargo en la respectiva contribución cuyos causales, auque fueron ciertos y pudieran influir para la adesión del Ayuntamiento nunca son bastantes para privar a éste de la facultad y arbitrio que tiene para volver a cerrarla...» Interrumpimos momentáneamente el relato para poner de manifiesto que las razones de los partidarios de la conducta abierta se basan en la deficiente asistencia y en su desacuerdo en cuanto a la distribución de los costes del servicio sanitario. Veremos cómo años más tarde se repiten los argumentos. Continuando con el pleno: «... maiormente en las actuales críticas circunstancias en que sólo se encuentran en este pueblo dos físicos que sobre no ser bastantes para la asistencia aun en estado de salud por lo extenso del pueblo y aun penoso en mucha parte por su situación local y crecido número de dos mil quinientos vecinos, el uno de ellos D. Antonio Palao se ha despedido y en efecto se hubiera marchado a otros pueblos en que le proponen partidas ventajosas a no haberle detenido este Ayuntamiento sin duda como así lo hizo presente por no poder subsistir con el corto número de igualados que tiene y omisión de éstos en el pago

3 AHMY, AC 22/6/1809. En este texto se hace referencia a la «conducta cerrada», concepto que alude a la contratación del médico con la obligación de atender a todos los vecinos, ya que todos contribuyen proporcionalmente a sus ingresos para el pago de los haberes del médico. Frente a ello se sitúa la «conducta abierta», también llamada «sistema de igualas», procedimiento mediante el cual el médico contrata sus servicios a familias de forma individual y voluntaria. Las controversias entre partidarios de uno u otro sistema son frecuentes, como veremos, en las primeras décadas del siglo.

4 AHMY, AC, 17/8/1802.

5 Obsérvese que el sistema supone obligar a los vecinos a establecer, mediante contribuciones, un sistema sanitario público que asegure la asistencia médica individualizada. No se trata de asistir sólo a los enfermos pobres, como ocurrirá a lo largo del siglo XIX, sino de disponer de un auténtico seguro sanitario de la comunidad, de tipo obligatorio. 
estipulado y conducta nada regular que observa el pueblo vajo de no quererse igualar hasta que por una enfermedad se ven en precisión en cuio caso aun tampoco pueden conseguir les satisfaguen o paguen cantidad alguna de lo que se halla bien cerciorado el Ayuntamiento...» Existe un doble juego de intereses. Por una parte los médicos no pueden subsstir en el pueblo debido probablemente a la miseria reinante, lo que supone que tengan pocos igualados y malos pagadores. Por otro lado, el Ayuntamiento quiere evitar que los médicos abandonen el pueblo y, para ello, no hay más solución que asegurarles unos ingresos fijos. Por ello, se razona en el acta que «...en caso de ausentarse dicho físico, preheviendo como prevee que sera dificultoso concurra otro alguno interin permanezca la conducta abierta... acordó: se cierre la conducta y que al instante se despachen circulares por los ss. D. Fernando Soriano y D. Juan Muñoz a quienes nombro comisarios, prefijando a los que quisieren pretender, el termino de cuarenta dias que se cumpliran el dia diez del proximo julio, cuio termino pasado no se recibiran memoriales y procedera el Ayuntamiento a señalar dia para la elección; previniendo los señores comisarios en las circulares que los facultativos que fueran admitidos han de obligarse por cinco años y que su dotación seran quinientos ducados pagados por tercios.» Esto es, el Ayuntamiento toma la decisión de cerrar la conducta y convoca un concurso libre para la provisión de las tres plazas de médicos municipales, para cinco años y con el sueldo y forma de pago que se estipula.

Pero la decisión suponía modificar el repartimiento de contribuciones que había de ser aprobado por instancias superiores; por ello, unos días después se establece que dicho repartimiento «... comprenda en el mismo, en casilla separada, los diez y seis mil y quinientos reales que por salario deben darse a los tres médicos que se han de nombrar... y que cuando se remita para su aprobación a la Intendencia se represente lo conveniente con testimonio en relación de la facultad real para poder nombrar» ${ }^{6}$. Desconocemos si la Intendencia consideró ajustadas a derecho las alegaciones aportadas por el Ayuntamiento basadas en el antiguo privilegio. Lo que sí sabemos es que el concurso se celebró y fueron nombrados D. Miguel Rubio Cervera, D. Antonio Palao Espejo y D. Dimas Joaquín Muñoz, siendo descartados D. Ginés López Andrés y D. Francisco Candela?.

La polémica se reproduciría algunos años más tarde, en 1839, según consta en el «EXPEDIENTE FORMADO POR EL AYUNTAMIENTO CONSITUCIONAL... PARA EL ESTABLECIMIENTO DE CUATRO MÉDICOS ASALARIADOS A CONDUCTA CERRADA $»^{8}$. Dicho expediente está encabezado por el acuerdo del

6 AHMY, AC, 21/6/1809.

7 AHMY, AC, 16/7/1809. Los avatares de la guerra impidieron la finalización del contrato por parte de los médicos, ya que en un informe del presidente de la Junta de Sanidad al Ayuntamiento, de 6 de agosto de 1812, sobre la construcción de un nuevo cementerio, figuran como médicos de Yecla D. Juan Llorca, D. Francisco Román y D. Dimas Muñoz.

8 AHMY, Leg. 476. 
Ayuntamiento de 20 de noviembre de 1839 , de «... asalariar cuatro facultativos de medicina para la combeniente asistencia de esta dilatada población», lo cual quiere decir, que en algún momento durante el reinado de Fernando VII se había vuelto al sistema de igualas. Para ello fue nombrada una comisión dirigida por el regidor D. Agustín Navarro y el síndico D. Francisco Bautista. Dicha comisión emitiría un largo informe en el que se analiza detalladamente la situación de la asistencia médica en la villa. Consideran no sólo útil sino también necesario «... que se haga un asentamiento cerrado con medicos... sin dejar la asistencia del pueblo a la medida de las igualas, perjudicial en su consecuencia a los vecinos y a los Profesores por mas que parezca a primera vista faborable a la libertad de los primeros...». Se vuelve a defender la asistencia comunitaria y obligatoria frente a las igualas voluntarias. Tras unas consideraciones sobre lo extenso del pueblo, el clima extremo y su situación en «...un terreno aspero y desigual y con diferentes rebueltas en sus calles altas», se refieren al número de habitantes diciendo que «... el censo de los contribuyentes es por lo menos de dos mil quinientos vecinos de esta clase ademas de personas miserables y otros que suman otros ochocientos...» Posteriormente entran a considerar el sistema de igualas (conducta abierta) aduciendo la frecuente falta de pago de las mismas, con lo que las familias llamaban al médico, no al comienzo de la enfermedad, sino cuando la gravedad era extrema y en ocasiones «...el medico solo es llamado para fallar la muerte». Ponen como ejemplo el exceso de muertes habidas en los años 1817, 1823 y 1826, que incluso llegó a llamar la atención de la Junta Superior de Sanidad, y achacan dicha mortalidad a «... la antedicha causa de haberse descuidado por el reparo de no haber pagado la higuala la apelación y asistencia de los médicos».

A diferencia del año 1809, en esta ocasión el Ayuntamiento tenía un soporte legal más claro. La Instrucción para el gobierno económico y político de las provincias de 3 de febrero de 1823, en pleno Trienio Liberal, era en realidad una Ley sobre Régimen Local. Esta importante ley, que constituiría un modelo para las posteriores leyes de régimen local, fue suprimida por Fernando VII en su segundo período absolutista y restablecida, tras su muerte, en octubre de 1836. Muñoz Machado ${ }^{9}$ divide las atribuciones de los Ayuntamientos que son conferidas por esta ley en dos tipos: unas funciones propias y otras delegadas por la Administración. Pues bien, las funciones propias son casi en su totalidad de carácter sanitario o relacionadas con la sanidad. Lo que aquí nos interesa es el artículo 12, en el que se especifica que los Ayuntamientos deberán procurar que «haya facultativo o facultativos en el arte de curar personas y animales, según las circunstancias de cada pueblo, señalando a los médicos y cirujanos la dotación correspondiente, a lo menos por la asistencia de los pobres, sin perjuicio de que si los fondos públicos lo pueden sufrir se extienda también la dotación de la asistencia sanitaria a todos los demás vecinos. Los facultativos serán

9 MuÑOz MACHAdO, S. (1995), La formación y la crisis de los servicios sanitarios públicos. Madrid. 
admitidos y contratados por el Ayuntamiento, pero si sus sueldos u honorarios se hubieran de satisfacer por igualas o repartimiento vecinal, sólo se sujetará a este pago a los que quieran servirse de los facultativos elegidos». Así pues, la ley vigente dejaba claro que el Ayuntamiento podía optar por uno u otro sistema según las disponibilidades económicas, lo cual ya era una fuente de conflicto entre los vecinos y también entre los médicos, pero es que además, admitía que en el caso de repartimiento vecinal, sólo se debía sujetar a este pago a los que (voluntariamente) quisieran servirse de los facultativos. En resumen la ley establece, al menos, la asistencia a los pobres (Beneficencia) y abre el camino a la función asistencial pública, si bien de forma voluntaria ${ }^{10}$.

Por otro lado, los ayuntamientos en toda España hicieron caso omiso de las normas dictadas por el Reglamento General de las Academias de Medicina y Cirugía de 31 de agosto de 1830, en el que se disponía que dichas academias tenían la facultad de proponer a los alcaldes las ternas de facultativos para su elección por parte de los ayuntamientos. Dicha norma fue incumplida sistemáticamente, de tal forma que nombraron y destituyeron a sus facultativos sin oír a las academias ${ }^{11}$.

A continuación, siguiendo con el expediente de 1839, se aportan unas consideraciones económicas referidas a que el sueldo de los médicos, de 5.000 reales anuales cada uno, suponía 20.000 reales, y que el pago de las igualas, a 18 reales, suponía 45.000 reales, con un ahorro comunal de 25.000 reales. El reparto del vecindario por cada médico supondría 625 vecinos a cada uno y se podría aprovechar la contrata para que uno de los médicos, el más antiguo, se hiciera cargo de la asistencia en el Hospital de Caridad, cobrando una cantidad extra aparte que no se especifica. Finalmente, el informe establecía el pago en tres plazos, abril, agosto y diciembre, y se abonaría con cargo al fondo de propios, efectuando un reparto entre vecinos por parte de la Corporación en caso de que faltara algo de dinero. El sistema, como puede apreciarse, parece razonable, al menos desde nuestro punto de vista actual, no en vano estaba inspirado en la legislación sobre régimen local emanada de los gobiernos del Trienio Liberal. Así lo consideraban los autores del informe, los cuales finalizan diciendo que si se adopta la propuesta «... se le proporcionará a esta villa Profesores de merito y se estimulara mas la aplicacion y el esmero de los que se nombrasen».

El nuevo Ayuntamiento presidido por D. Jacinto Esteve, el 8 de junio de 1840, expone el proyecto a la consideración de los vecinos mediante edictos situados por la población, sometiéndolo, a votación pública, un procedimiento que no hemos visto

10 En palabras de Muñoz Machado, «Es ésta la primera manifestación, aunque su contenido sea parcial, de la asunción por la Administración del cuidado de la salud individual, es decir, que estamos ante la primera declaración constatable hasta ahora de actividad pública sanitaria de carácter asistencial... es de tomar en cuenta el dato de esta primera manifestación (en cierto modo extemporánea en relación con las ideologías reinantes), que de haberse fortalecido podría haber sumado al tradicional sector preventivo el asistencial como obligada prestación de la Administración pública».

11 Albarracín Teulon, A. (1969), p. 36. 
reflejado en la bibliografía consultada sobre el nombramiento de médicos titulares en esa época. La Diputación había acordado el 17 de febrero autorizar al Ayuntamiento a que «... formalice concejo abierto y que con su resultado se le devolviera el expediente para acordar lo mas conforme». Durante ocho días estuvieron abiertas las salas capitulares para que los vecinos, sin distinción de clases, «...digan lo que quieran desde las nueve a las doce y desde las tres a las seis por la tarde entendiendo que el que no pase se considera que esta conforme con el proyecto». En las actas de la «votación» vienen reflejados más de setecientos vecinos en contra del proyecto. Ante este inesperado resultado del concejo abierto, el Ayuntamiento decide investigar las causas del mismo y la situación en ese momento del sistema de igualas, preguntando a cada uno de los médicos ${ }^{12}$. En total existían 1.192 vecinos igualados, pero con un muy desigual reparto entre los médicos, ya que D. Basilio Amat Vallejo tenía igualados a casi la mitad. Del resultado de la lectura de este largo expediente se deduce que la comisión encontró razones para creer que los votos negativos habían sido manipulados, precisamente por D. Basilio Amat, mediante la distribución del rumor de que se iban a aumentar las contribuciones, la utilización de personas forasteras, la destrucción de pasquines informando a la población del concejo abierto, etc. Se interrogó a testigos que afirmaron haber oído decir a D. Basilio «... digan ustedes que estan conmigo y que no necesitan mas medico».

El inforrme final de la comisión contabiliza 734 votos en contra del proyecto y más de 1.700 a favor, y considera que D. Basilio Amat ha urdido una intriga que ha falseado el resultado de la votación. Sobre la necesidad de médicos asalariados afirma que «... en las ciudades donde no hay Hospital de rentas considerables donde puedan entrar los vecinos ni hay grandes propietarios ni títulos, corporaciones, comunidades o gremios que den largas remuneraciones a los facultativos es necesario tener medicos asalariados y contratados. De lo contrario sin incentivos no habría

12 Resumimos las contestaciones a los oficios del Ayuntamiento preguntando a cada uno de los médicos sobre el número de igualados que tienen:

D. Pedro Serrano contesta que tiene 25 igualados, de los cuales dos lo están con otro médico.

D. Juan Carpena: 32 igualados.

D. Bartolomé Ortega Muñoz: 200 igualados.

D. Salvador Muñoz Cerezo: 24 igualados.

D. Simón Polo, Subdelegado de Medicina: 350 igualados. Aclara que algunos «... cumplen regularmente conmigo y por lo mismo me avisan sin reparo al tener algún enfermo... [pero]... han desertado más de la mitad y han fallecido muchos sin asistencia o en manos de curanderos porque avergonzados de su ingratitud y abandono no se han atrevido a reclamar mi asistencia».

D. Basilio Amat y Vallejo: 586 igualados «... debiendo rebajar a lo menos ciento que por insolventes hace tres años ni ellos cuentan conmigo ni yo con ellos».

Al mismo tiempo se cursó un escrito a D. Lucio Ortuño, Presbítero Administrador del Hospital de Caridad solicitando información sobre las rentas del hospital, el número de enfermos anuales y sobre si son transeuntes o naturales de la villa, a lo que contesta que las únicas rentas son las limosnas de dos o tres personas piadosas y que se asiste a dos o tres enferrnos diarios de los que un $50 \%$ son forasteros. 
médicos». Además, recuerdan que, de los 2.500 vecinos, sólo hay poco más de mil igualados, preguntándose que ¿cuántos de los que han votado en contra no tienen médico? Concluyen recomendando que se lleve a cabo el proyecto.

El expediente fue enviado a mediados de julio a la Díputación para su aprobación definitiva, pero fue devuelto en octubre con la recomendación de que se volviera a celebrar concejo abierto, aunque esta vez «... en dias feriados consecutivos y con la diferencia de que el que no asista se considerara que esta en contra del proyecto». Desgraciadamente desconocemos si se 1levó a cabo esta segunda votación, aunque sospechamos que no, pues no hemos encontrado más referencias en las actas municipales.

Si nos hemos extendido en el relato de este expediente es para destacar que fue el único intento serio en todo el siglo XIX de establecer una asistencia sanitaria individualizada para toda la población. Durante la segunda mitad del siglo y las primeras décadas del XX, la asistencia sanitaria municipal se limitó a los listados de pobres, a la vigilancia de epidemias y a cuestiones relacionadas con la higiene pública, como describiremos a continuación.

\section{LA LEY DE SANIDAD DE 1855. LAS JUNTAS DE SANIDAD Y LOS SANITARIOS TITULARES}

La Ley sobre el Servicio General de Sanidad de $1855^{13}$, consolida las reformas realizadas a lo largo de la década de los cuarenta, sustancialmente el Reglamento del Consejo y las Juntas de Sanidad de 26 de marzo de 1847 y el Reglamento de los Subdelegados de Sanidad del 14 de julio de 1848.

A partir de dicha ley, el órgano supremo de la Sanidad española será la Dirección General de Sanidad, que tendrá, como órgano consultivo al Consejo de Sanidad del Reino. En el ámbito local, los subdelegados de Sanidad serán unos agentes delegados de la Administración central en cada partido judicial. Su misión consistía en la vigilancia y exigencia del cumplimiento de las disposiciones que, en materia sanitaria, emanaban del gobierno a través de la Dirección General de Sanidad. En cada partido debía haber tres subdelegados de Sanidad: uno de Medicina y Cirugía, otro de Farmacia y otro de Veterinaria, todos ellos nombrados por el gobernador civil a propuesta de la Junta Provincial de Sanidad. Dichos funcionarios actuaban como superiores inmediatos de los facultativos de distrito. En opinión de Muñoz Machado ${ }^{14}$, la introducción en el sistema sanitario de la figura del subdelegado de Sanidad, no supuso que se descargase a los entes locales del sostenimiento económico del sistema y sí, en cambio, supuso una «importante intromisión de la Administración centralizada en

13 La ley fue elaborada y publicada en pleno Bienio Progresista el 28 de noviembre de 1855.

14 MuÑOZ MACHADO, S. (1995), p. 39. 
los asuntos que les estaban conferidos a los Ayuntamientos». Lo cual contrasta con el espíritu liberal y descentralizador que caracterizó al bienio 1854-56.

La nueva ley prohibía la adopción del sistema cuarentenario en general, obligaba a todos los ayuntamientos a crear la Beneficiencia domiciliaria mediante médicos cirujanos y farmacéuticos titulares y se establecían normas para la venta de medicamentos, prohibiendo los remedios secretos y estableciendo los requisitos que debían exigirse a las recetas. Finalmente, la ley establecía la obligatoriedad de la vacunación antivariólica y disponía que se publicase un Reglamento especial conteniendo las reglas higiénicas a que debían estar sujetas todas las poblaciones ${ }^{15}$.

En cuanto a las Juntas de Sanidad, se mantenía el Reglamento, al que hemos aludido, de marzo del 47. Debían constituirse en los municipios de más de mil habitantes. Estaban presididas por el alcalde y se componían de un médico, un cirujano, un farmacéutico y un veterinario, además de tres vecinos. eran órganos estrictamente consultivos de la autoridad política y podían proponer medidas extraordinarias a la alcaldía, que era la encargada de ejecutarlas.

Por su parte, los facultativos titulares contratados por los municipios tenían como misión atender a las familias pobres de la localidad, asesorar al Ayuntamiento en materia de policía sanitaria y, en caso de epidemia, estaban obligados a no ausentarse del pueblo, podiéndoseles exigir el que sus servicios se prestaran al total de la población; sin embargo se mantenía el libre ejercicio de la profesión en el ámbito de actuación de los titulares.

\section{La higiene pública}

Hasta aquí hemos expuesto a grandes rasgos la organización sanitaria municipal que establecía la Ley de 1855. En los años previos a la Ley, aparecen frecuentemente, en las Actas Capitulares y en los bandos de la alcaldía, referencias a aspectos relacionados con la higiene pública y el urbanismo. El ayuntamiento no disponía de los servicios y el personal necesario para estas cuestiones, por lo que sistemáticamente se responsabilizaba a los vecinos del cumplimiento de las normas propuestas por la Junta de Sanidad. Uua cuestión que preocupa a la Junta se refiere a las basuras y el estiércol generado en casas y corrales, por lo que se establecen normas para su eliminación: «... la extracción de los estiercoles se haga durante las horas de la noche o primeras de la mañana depositando estos en la vereda llamada del Algibe desde la bajada del molino de viento y al poniente desde la senda conocida de Simon Santa en direccion al camino de Jumilla exceptuando los sitios por donde corren las aguas. Se prohibe asi mismo depositar las caballerías y animales muertos en las inmediaciones

15 BÉCARES, F. (1935), Técnica Sanitaria Municipal, Artes Gráficas Afrodisio Aguado, Valladolid. 
de la población y si solo en el cerro llamado de las Trancas y en el de las Serratillas» ${ }^{16}$. Como veremos, a lo largo de todo el período, aparecen multitud de recomendaciones referentes a la limpieza de calles, el depósito de basuras y animales muertos en las afueras de la población. Las calles, sin embaldosar ${ }^{17}$, recibían todo tipo de inmundicias, basuras, aguas de origen doméstico además de estar repletas de obstáculos, pues servían como «talleres» de las más diversas profesiones. En un bando de 1853, el Ayuntamiento ordena que «...se quiten los poyos, piedras, vancos de carpinteros y aperadores, piedras sueltas y demas estorbos en el preciso termino de ocho dias, cuidando cada vecino de sus respectivas afrontaciones» ${ }^{18}$.

También preocupan las condiciones de las viviendas, según se desprende de las normas a los maestros alarifes, por las que se les recomienda que «... esta coporacion, sabedora de los perjuicios que ocasiona la subdivision de viviendas que en pequeñas casas se practican de algun tiempo a esta parte... no procedan a hacer particion alguna de casas sin que preceda licencia escrita del Ayuntamiento previa la correspondiente exposicion.... ${ }^{19}$. El problema fundamental se sitúa en las zonas altas de las cuevas, donde las infecciones se desarrollan con más frecuencia, circunstancia que no pasa desapercibida a la Junta de Sanidad: «... la enfermedad que nos aflige ataca principalmente a los vecinos que habitan cuevas insalubres y poco ventiladas... que de los fondos destinados a calamidades publicas se socorra a los mas pobres y necesitados que ocupan aquellas, con el fin de que salgan a los campos o a otros puntos y puedan abandonar sus moradas que son los focos de infecciónn mas temibles» ${ }^{20}$. Pero la construcción de cuevas continúa en los años sesenta, en las zonas de Serratillas, Cerro del Castillo y San Cristóbal, con malas condiciones de habitabilidad: «... lo insalubres que son y el riesgo para la salud pública sin condiciones de ventilación ni desahogo, con peligro inminente de hundimiento» ${ }^{21}$. La población había aumentado en diez años en cerca de 3.000 personas $^{22}$, situándose a principio de los sesenta en más de 12.000 habitantes, por lo que la escasez de viviendas era un problema acuciante. En abril del 67 se hace constar en el pleno que «... teniendo presente, el aumento de poblacion y lo dificil que es a muchos de los vecinos de esta villa procurarse habitaciones en razón de la escasez de estas y por no haber sitios a proposito para la edificacion de casas, muchos se han dedicado a construir cuevas con grave perjuicio de la salud publica».

16 AHMY, leg. 11. Bando de la alcaldía de 11 de mayo de 1853.

17 Los primeros pavimentos en las calles de Yecla se colocan en 1853 en algunos tramos de las calles de San Francisco, Niño, Nueva, San Antonio y San José (AHMY, AC SO 17/3/1853).

18 AHMY, AC SO 17/3/1853.

19 AHMY, AC SE 19/3/1853 y SO 11/10/1853.

20 AHMY, AC SO 6/10/1859.

21 AHMY, AC SO 22/11/1866.

22 Nomenclátor de la Provincia de Murcia de 1860, MOPU, Murcia. 
A finales de la década de los cincuenta se divide el pueblo en cuatro zonas (Hospital, San Cristóbal, Santa Bárbara y San Roque) y se encarga a cada una de ellas a un conceja1 para la vigilancia del aseo, limpieza y salubridad de la misma, estableciéndose multas a aquéllos que arrojen a la calle aguas sucias o basuras, repitiéndose la recomendación infinidad de veces en bandos y edictos. Pero es evidente que el vecindario hacía caso omiso a las recomendaciones; sirva como ejemplo ]a protesta que se produce en el Ayuntamiento por la deplorable situación de un callejón entre la calle del Niño y la calle Nueva en $1860^{23}$

Asimismo se establecen en esos años los lugares de lavado de ropa de enfermos y sanos en un bando de 23 de diciembre de 1859: «... se hace saber a todos los vecinos que como medida de precaución se designa para labado de las ropas de los enfermos de cualquiera clase que sean, las aguas de San Isidro, dejando los demas puntos de labadero del agua viejo para labar las ropas de los sanos». Unos años más tarde se vería con buenos ojos en el Ayuntamiento la propuesta de un particular para la construcción de un lavadero público, pero desconocemos si la obra se llevó a cabo en esa época ${ }^{24}$.

Otra preocupación de la Junta de Sanidad es la referente al sumininistro de alimentos a la población. Las condiciones del matadero municipal son objeto de numerosas alusiones en los plenos. El 14 de julio de 1859, en contestación a una circular del Gobierno Civil, se informa que el matadero «... no reune las circunstancias salubridad, ventilación y demas requisitos prevenidos», por lo que se está pendiente de la construcción de un nuevo edificio. Se describen las normas existentes en ese momento refiriendo que «... matan por la tarde en el verano colocando las reses en un cuarto enjugador y a la mañana siguiente se inspeccionan las que en el dia anterior lo fueron vivas». Para esta inspección están nombrados un facultativo de medicina, un veterinario y un práctico. No existían empleados y la limpieza y el sacrificio de las reses corría a cargo de los expendedores. También el traslado de las carnes desde el matadero a la carnicería municipal es objeto de una normativa por la que «... se acuerda la subasta para la conducción de las expresadas carnes con carro que reuna las condi-

23 «... que en la rinconada del callejón que baja de la calle del Niño Jesús a la Nueva con direccion al Posito de Labradores... se colocan o ponen toda clase de inmundicias o escombros por personas que no es facil descubrir porque esta operacion la hacen regularmente a altas horas de la noche con el fin de no ser vistos por otros, colocando tambien animales muertos, produciendo estos depositos o focos de infeccion tan mal hedor que no es posible el transito de persona alguna por este punto por la porcion de miasmas putridas que exhalan y que corrompiendo el aire atmosferico es facil el desarrollo de cualquier enfermedad epidemica o contagiosa» AHMY, AC SO 6/9/1860.

24 A solicitud de Cristóbal Gómez Tevar, dueño del Huerto de las Ánimas, se propone al Ayuntamiento «... construir un labadero para el servicio publico en el cual con una modica retribucion puedan las labanderas labar con comodidad aseo y limpieza» AHMY, AC SO 27/3/1862. 
ciones necesarias para evitar el polvo e inmundicias que dichas carnes recogen en su transito de conduccion» 25 .

A partir de la creación en junio de 1863 de una Junta de Policía Urbana, emanada de la Junta de Sanidad ${ }^{26}$, se observa un mayor celo en la vigilancia del cumplimiento de multitud de normas de salud pública. Se vigila la posible adulteración de alimentos en cafés y posadas, las fábricas de jabón y encurtidos para su limpieza y extracción de residuos, el lavado de ropas, las condiciones de las letrinas particulares, los baños de animales, etc. ${ }^{27}$ Las atribuciones en materia de sanidad son tomadas muy en serio por la Corporación en esos años. Se vigilan muy especialmente los cauces del agua, procurando evitar su contaminación, fundamentalmente por el lavado de ropa y por los deshechos de las fábricas, recomendando «... tapar a cal y canto los conductos que tengan comunicacion entre la acequia y las balsetas de las fabricas» ${ }^{28}$.

La llegada de la Restauración marcará un cambio de ritmo en lo que a la higiene pública se refiere. A partir de 1874 y hasta finales de siglo, además de la insistencia en las medidas de limpieza pública que hemos descrito para los años sesenta, los servicios del ayuntamiento acometen dos tareas fundamentales: por un lado, durante las décadas de los setenta y los ochenta, el arreglo de calles (rasantes, cerrado de albañales, pavimentaciones, etc.) y, a partir de 1893, se empiezan a elaborar planes para la conducción de aguas potables a la población.

Pero, en lo que se refiere a la limpieza de la población, la situación deja mucho que desear, a juzgar por la descripción que se hace, en la sección de Crónica de $L a$ Soflama, periódico de la oposición al alcalde conservador Moncada, del lastimoso estado sanitario de las calles de la población, con suciedad e inmundicias, no sólo en callejones sino también en calles: «... la fuente principal se encuentra convertida en una inmunda charca, de donde salen aguas que se destinan al consumo, arrastrando masas y filamentos de ovas que, sobre inspirar repugnancia, comprometen la salud pública» ${ }^{29}$.

El proceso de conducción de aguas potables a Yecla, que habría de tener una importancia crucial en la disminución de la morbi-mortalidad a partir de las primeras

25 AHMY, AC SO 15/6/1863.

26 En otras poblaciones se llamaría Comisión permanente de salubridad pública (AYALA, J. A. (1977), «Medicina preventiva en Murcia: La Junta Municipal de Sanidad (1849-1900)», Medicina e historia, vol. 64, 8-26).

27 AHMY, leg. 12, 1861.

28 En la SO de 30 de agosto de 1865 , se da cuenta que «... los oyos de las fábricas de aguardiente contienen un olor intolerable... citándose a todos los fabricantes para que en el plazo improrrogable de cuatro días... cubran los hoyos con palos y leña menuda y encima paja apisonada. Que no toquen las heces que tienen y que las que hagan a partir de ahora las saquen a las afueras en los sitios señalados». Similares normas se impartieron a las fábricas de encurtidos y almazaras. En las tenerías se insistía que se aislaran del cauce principal «...para que las legias y zumaque que producen no contaminen el agua».

29 AHMY, Libro 2087. La Soflama, año II, n. ${ }^{\circ} 29,1892$. 
décadas del siglo XX, se inicia en la sesión de 18 de octubre de 1893, en la que se solicita a la Diputación un ingeniero de minas para «... practicar los estudios necesarios para la conduccion de aguas potables para el abastecimiento de esta poblacion y asi mismo que dispongan la venida del arquitecto provincial para el levantamiento de los planos de las obras que se proyecten». Sin embargo no aparecen más referencias en las Actas Capitulares hasta 1899, cuando se recogen dos propuestas privadas para la instalación. A la primera, de agosto de 1899, presentada por D. José Segura Sánchez, de Madrid ${ }^{30}$, el Ayuntamiento, presidido por Martínez Peiró, le impone una serie de condiciones como son, por supuesto, las buenas condiciones de potabilidad del agua, el establecimiento de, al menos, seis fuentes o kioscos públicos y la posibilidad de establecer abonados particulares. Además, el Ayuntamiento se reserva cuatro metros cúbicos diarios para Beneficencia, agua suficiente y gratis en caso de incendios y una reducción del precio a la mitad en caso de epidemias. El plazo de las obras no podía superar los dos años. En la segunda propuesta, de D. Pascual Cantos Falceto, de Bañeres ${ }^{31}$, se especifica además el precio del agua, que sería de una peseta por metro cúbico para el Ayuntamiento y 1,5 pesetas para los abonados particulares, reservándose el Ayuntamiento ocho metros cúbicos para Beneficencia. Parece ser que fue la primera propuesta la aceptada ${ }^{32}$.

\footnotetext{
30 AHMY, AC SE 3/8/1899.

31 AHMY, AC 29/11/1899.

32 En la sesión supletoria de 4 de julio de 1900 figura una memoria elaborada por la Comisión Municipal de Aguas, presidida por D. Francisco Antonio Martínez Peiró, de la que a continuación exponemos un extracto: se trata de una colección de hechos, incidentes y festividades relacionados con la traída de las aguas potables a la población, escrito con ampulosidad y autocomplacencia, pero con indudable valor histórico. Justifican el informe para «... hacer resplandecer la verdad histórica sin falseamientos que la alteren u obscurezcan y sacrificando la fantasia a la certeza en la exposicion». Refiere que el pueblo ha entrado «... en el concierto de las grandes poblaciones por el fomento de su agricultura» y se han acometido reformas como «... la reparacion de la plaza de Abastos, la Carniceria y el edificio destinado a la expedición de pescados... fueron arreglados los caminos y puestas las calles de la ciudad conforme a las exigencias de una villa moderna...» Se recuerda el viejo anhelo de la población desde hacía años de traer las aguas potables y la realización de viejos estudios y planificaciones que nunca se habían llevado a cabo, hasta la concesión a la empresa de los señores Segura. Dicha empresa hizo prospecciones en los altos de Caudete sin resultados para comprar posteriormente el manantial, ya alumbrado, de la Casa de la Roja y posteriormente construyó un depósito de aguas y realizó el zanjeo y colocación de tubos hasta la población.

Continúa la memoria relatando la inauguración del referido depósito «...estando representadas todas las clases sociales, agricultores, industriales, obreros, curia, clero, abogacia, medicina... con un suntuoso banquete a cuya terminacion y a las primeras aguas que cayeron en el recipiente se pronunciaron entusiastas brindis y se dieron calurosos vivas al ayuntamiento y a la empresa de aguas». Unos días después se inauguran dos fuentes públicas, para lo que se pusieron colgaduras e iluminaron los balcones. Se habla de una «ingente muchedumbre» que acude a la iglesia de la Concepción donde «con la cruz alzada» se bendicen las aguas. Una de las fuentes se había colocado en la plaza del Colegio instalándose una manga de riego en la calle de San Francisco y celebrándose un segundo banquete en el Teatro con trescientos invitados por cuenta de la empresa. Aquella noche se celebró una verbena en la Glorieta con banda de
} 
La compañía de los Segura cedió sus derechos en 1901 a la Compañía General de Aguas Potables de Yecla, la cual presentó presupuesto ${ }^{33}$ para la instalación de agua en los establecimientos públicos. El agua llegó en primer lugar al Asilo-Hospital en septiembre de 1903 y posteriormente al Matadero y a la Carnicería.

\section{Las Juntas de Sanidad}

Hasta la entrada en vigor de la Ley de Sanidad en 1855, las Juntas Municipales de Sanidad ${ }^{34}$ estaban compuestas por el alcalde, que hacía de presidente, un teniente de alcalde, dos regidores y dos individuos de la Junta de Beneficencia. En cuanto a los técnicos, había dos licenciados en Medicina y un farmacéutico. El motivo principal de la creación de dichas juntas era el de organizar la defensa colectiva frente a las epidemias, por lo que el mayor número de actas conservadas en la segunda mitad del siglo XIX se refieren casi siempre a los años en que el cólera amenazó a la población.

De 1854 y 1855, por ejemplo, se conservan un buen número de actas a partir de la constitución, el 7 de agosto de 1854, de la Junta Municipal de Sanidad con motivo de los rumores de epidemia de cólera. Es probable que la Junta no se hubiera constituido desde hacía al menos veinte años, ya que en el pleno del Ayuntamiento se acuerda que «...se nombre una Junta de Sanidad para que tomando en consideracion lo mucho que sufrió este vecindario el pasado año de mil ochocientos treinta y cuatro se ocupe de deliberar las medidas que nos conduciran a lograr el fin deseado» ${ }^{35}$. La composición de la Juntas no siempre se ajustaba estrictamente a lo establecido en la Real Orden de 18 de enero de 1849 para las Juntas del interior, ya que, por ejemplo, en 1854 formaban parte de ella, además de los médicos y el Regidor Síndico, los presbíteros tenientes de ambas parroquias y los mayores contribuyentes. La misión de la Junta se concretaba en la defensa de la salud colectiva de la población mediante el establecimiento de cordones y lazaretos, división del pueblo en cuarteles para la asistencia de los facultativos titulares a los enfermos pobres y para la puesta en marcha de medidas higiénicas y de desinfección, reparto de socorros, como alimentos, dinero o medicinas, etc. El dinero era siempre escaso para atender a las necesidades de la Junta y se obtenía siempre del fondo de calamidades, suscripciones públicas, donaciones y, en última instancia, del capítulo de imprevistos. En ocasiones, la Junta de Sanidad establecía comisiones formadas por un médico y tres vecinos que se encar-

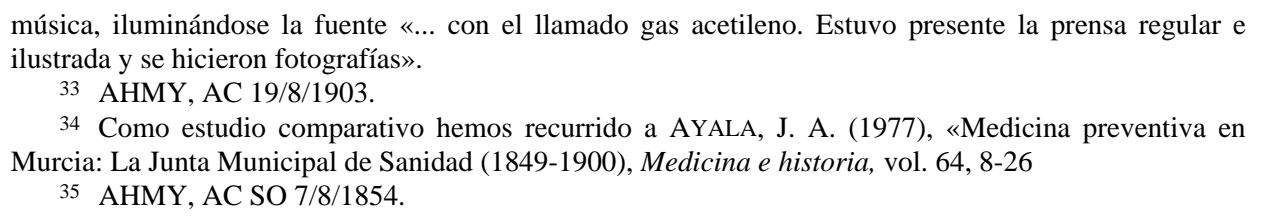

34 Como estudio comparativo hemos recurrido a AYALA, J. A. (1977), «Medicina preventiva en Murcia: La Junta Municipal de Sanidad (1849-1900), Medicina e historia, vol. 64, 8-26

35 AHMY, AC SO 7/8/1854. 
gaban de visitar las casas de los enfermos, en los cinco distritos en que se dividía el pueblo, y aconsejar a las familias sobre medidas de desinfección y limpieza. Asimismo, se encargaban de facilitar a las familias pobres vales o bonos para la adquisición de desinfectantes ${ }^{36}$.

Otra misión de la Junta era la elaboración de informes para el Gobierno Civil referentes a la aparición de enfermedades o sobre el estado sanitario de la población, misiones de las que se encargaban los componentes técnicos de la Junta. De estos informes, el más completo que se conserva se refiere a la epidemia de cólera de $1885^{37}$, donde se recoge una relación diaria de afectados y fallecidos, con expresión de sus edades, sexo, profesión y estado civil.

A partir de la Restauración, la Junta interviene más a menudo en cuestiones de higiene pública en ausencia de epidemias. En 1890 se celebra una reunión extraordinaria $^{38}$ en donde, después de acordar reunirse todos los sábados a las seis horas de la tarde, se hace referencia a la vigilancia de mercados y establecimientos de comestibles, así como de cuadras y patios, manifestando «... la salud inmejorable que se disfruta en esta vecindad y la mucha higiene que han encontrado en los establecimientos publicos y privados que llevan inspeccionados».

\section{Los facultativos titulares en la segunda mitad del siglo XIX}

La ley del 55 autorizaba a los ayuntamientos a contratar facultativos para establecer la hospitalidad domiciliaria (Beneficencia) para familias pobres, además de para «auxiliar con sus consejos científicos a los municipios en cuanto diga relación con la policia sanitaria» ${ }^{39}$. Así, a partir de esta ley, la posibilidad de establecer «conducta cerrada» desaparece, por lo que el sistema de igualas o el simple pago por acto médico se generaliza para el resto de la población. Los médicos no tuvieron más remedio que aceptar los escasos emolumentos que les ofrecía el Ayuntamiento. En el mismo año de 1855, los cuatro médicos titulares de Yecla «...enterados que fueron de las condiciones del presupuesto municipal formado para este año y de la percepción del sueldo señalado en el mismo a los profesores titulares, combinieron en aceptar las expresadas condiciones y repartirse por partes iguales la retribución y el trabajo... si bien atendiendo a lo mezquino de la dotacion combinieron tambien en formalizar una exposición para que se amplie, lo que en caso de obtenerse se distribuiría entre los interesados por partes iguales lo mismo que el sueldo anterior».

36 AHMY, leg. 479.

AHMY, leg 483.

8 AHMY, leg 479. Acta de la sesión extraordinaria de la Junta de Sanidad del 19 de junio de 1890.

39 Cf. MuÑOZ MACHADO, Santiago (1995), p. 42. 
De hecho la situación de los médicos titulares en esa época era de gran malestar ante la sociedad, por el empeoramiento de su estatus económico y de su consideración social respecto a décadas anteriores ${ }^{40}$. En 1865 , el sueldo de un médico titular es de 4.000 reales anuales, con la obligación de atender a doscientas familias pobres, y un sobresueldo de 25 reales por cada familia que exceda de dicho número ${ }^{41}$.

En 1865 se firma un contrato con los cuatro médicos que aparecen en las Actas de la Junta de Sanidad de la época. Dicho contrato fue renovado en 1869 y, luego, tácitamente mantenido con los mismos facultativos hasta junio de 1877. En dicha renovación, por otros ocho años ${ }^{42}$, se especifica que cada médico dará asistencia a trescientas familias pobres y que la dotación será de 975 pesetas por médico-cirujano y 1.025 pesetas a los partidos servidos por médicos y cirujanos (625 pts. al médico y 400 al cirujano), pagaderas por trimestres vencidos. La Revolución del 68 había establecido un nuevo reglamento para organizar la asistencia a los pobres en los municipios, según el cual, en las poblaciones de más de 4.000 habitantes se establecía la hospitalidad domiciliaria, se especificaban las obligaciones de los facultativos y se definía la consideración de «pobre» para tener derecho a asistencia. Pero la situación seguía siendo precaria para estos servicios. Los ayuntamientos podían destituir y nombrar facultativos a su antojo, las dotaciones siempre eran escasas y no siempre se pagaban. Los médicos eran separados del servicio por motivos nimios y, en algunos pueblos, la ausencia de clientela privada convertía la provisión de las vacantes en una subasta a la baja ${ }^{43}$.

En el caso de Yecla no tenemos constancia de que se produjeran arbitrariedades de este tipo. De hecho, los contratos se mantuvieron, para los mismos médicos, durante un largo período de años.

\footnotetext{
40 A este respecto es interesante hojear lo que se escribe en la prensa profesional de la época: «... los médicos y cirujanos tienen que reducirse... a celebrar contratos con los pueblos por cantidades generalmente inferiores a las que disfrutaban treinta años hace, cuando su gasto no ascendería a la mitad de las asignaciones que gozaban, con lo que realmente han duplicado su pobreza, tocando ya en un deplorable y vergonzoso extremo.» Siglo Médico, III, 302-303, en ALBARRACín TEULON, A. (1973), «La profesión médica ante la sociedad española del siglo XIX», Asclepio, vol XXV, 303-316.

41 AHMY, AC SE 23/5/1865.

42 Hasta 1868, la titulación médica española es un auténtico caos constituido por las siguientes categorías: licenciado y doctor en Medicina, licenciado y doctor en cirugía médica, licenciado en cirugía, médico-cirujano, Doctor en ciencias médicas, cirujano de primera clase, cirujano-sangrador, cirujano de cuarta clase, Práctico en el arte de curar, ministrante, facultativo de segunda clase y partera. A partir de la Restauración las titulaciones se limitan a las actuales, pero permanecerán las titulaciones antiguas, a extinguir, hasta las primeras décadas del siglo XX (Albarracín Teulon, A. (1969), «La titulación médica en la España del siglo XIX», Actas del III Congreso Nacional de Historia de la Medicina, Valencia, 27-34).

43 Albarracín Teulon, A.(1969), p. 40.
} 
En 1883 se celebra un nuevo contrato con tres médicos y dos cirujanos ${ }^{44}$, en el que se mantienen los emolumentos de treinta años antes: 999 pts. a los médicos y 625 a los cirujanos. Al menos, en la década de los ochenta, a los facultativos se les reconoce su labor desde la Administración, según se desprende de un artículo publicado en El Consultor de los Ayuntamientos, una revista de la Administración Local. En dicho artículo se describe bastante detalladamente la situación de los médicos titulares en la década de los ochenta, por lo que a continuación extractamos los pasajes más significativos: «Los Médicos titulares, sobre formar un cuerpo numeroso de servidores de los pueblos, prestan servicios tan humanitarios, tan expuestos y de tan elevado interes social... visitan un número determinado de familias pobres, de $150 \mathrm{a}$ $200 \mathrm{y}$ aun mas, por la retribucion de 3.000 o de 4.000 rs.; la que llega a 5.000 es una cosa notable. En la designación de pobres suele haber muchos abusos; pero no es esto lo peor, sino que unas veces por falta de fondos, otras por rencilla de localidad, pasa un trimestre y otro y otro y no se satisface la asignación. De aquí pasa al igualatorio de los acomodados; todos quieren pagar poco, raro es el que se muestra razonable y desprendido; igualas de 16, 20 y $24 \mathrm{rs}$. al año por familias de cuatro o mas individuos, de suerte que para reunir otros cuatro o cinco mil rs. necesita otros 150 ó 200 igualados... lo cual lleva en si el sacrificio de la sujección constante, las visitas nocturnas, el haber de luchar contra los temporales y con las dificultades de la cobranza de las igualas... de estos ilustre servidores del Estado, de los pueblos y de las familias, nadie se acuerda mas que en los críticos momentos de una terrible epidemia... en resumen: bajo el punto de vista científico están muy poco considerados; bajo el económico, muy mal retribuidos; y bajo el de funcionarios públicos, colocados en el último lugar de la escala...» ${ }^{45}$.

Desconocemos las circunstancias en las que desarrollaron su trabajo los médicos titulares de Yecla, así como el nivel de ingresos de los mismos mediante el sistema de igualas. De los documentos oficiales consultados no se desprende que existieran dificultades con la administración del Ayuntamiento en cuanto al tipo de trabajo, número de médicos, sueldos, etc.

En 1891 se reunió en Madrid un Congreso de Médicos Titulares en el que se reivindicaron dotaciones fijas garantizadas por el Estado, oposiciones nacionales para el ingreso en el Cuerpo, con la creación de una escala y provisión reglamentada de vacantes y el establecimiento por parte del Estado de los derechos pasivos; pero la situación continuó sin variaciones hasta 1904, cuando se publica la Instrucción General de Sanidad.

44 Médicos: D. Pascual Ortega, D. Miguel Azorín y D. Honorato Maestre. Cirujanos: D. Pascual Candela y D. Antonio Gil (AHMY, AC SE 1/7/1883).

45 El consultor de los Ayuntamientos, 1885, «Secretarios y Médicos. Los de los Ayuntamientos y los titulares», 300-301. 


\section{LA SANIDAD PÚBLICA EN YECLA EN LAS PRIMERAS DÉCADAS DEL SIGLO XX}

En 1904, el gobierno de Maura aprueba la Instrucción General de Sanidad, un decreto que, originalmente, estaba proyectado como Ley General de Sanidad para sustituir a la de 1855 .

En lo que se refiere a los municipios, se consolidaba la figura del Inspector Municipal de Sanidad, cargo que era ocupado en los pueblos cabezas de partido judicial por el anterior Subdelegado de Medicina, con las mismas competencias que venía ostentando. La financiación continuó a cargo de los municipios, a pesar de que el espíritu de la ley apuntaba a un mayor fortalecimiento de la rama periférica sanitaria de la Administración central ${ }^{46}$.

Las Juntas de Sanidad, aunque se mantuvieron, quedaron como meros órganos consultivos vacíos de competencias.

Quizá el aspecto más interesante de la Instrucción, en lo que a la Sanidad Municipal se refiere, fue la regulación del Cuerpo de Médicos Titulares: en cada municipio debía existir un médico titular y un practicante por cada trescientas familias pobres, siendo los contratos por tiempo indefinido. Para ingresar en el Cuerpo de Médicos Titulares era preciso superar una oposición, lo que suponía la consecución del «... diploma de aptitud especial para médicos titulares ${ }^{47}$, condición necesaria para ser contratado por un ayuntamiento. Las vacantes en los ayuntamientos habían de ser comunicadas a la Junta del Protectorado y Gobierno de Médicos Titulares, la cual enviaba a los alcaldes un listado de los titulares que podían optar a ellas tras la celebración de un concurso.

También se regulaba la constitución de partidos farmacéuticos y veterinarios.

Finalmente, la Instrucción establecía normas para cuestiones de higiene pública relacionadas con el suministro de aguas y evacuación de residuos, viviendas, establecimientos y servicios higiénico-sanitarios, mercados, mataderos, industrias insalubres, etc. Asimismo, se establecía un servicio de estadística y la obligación de declarar determinadas enfermedades infecciosas ${ }^{48}$.

La situación de la higiene pública en Yecla a principios de siglo puede estimarse por el informe emitido por el Inspector Provincial de Sanidad, con fecha de 13 de octubre de 1910, a petición del alcalde D. Antonio Ortega Coya ${ }^{49}$. En dicho informe se hace referencia a la situación sanitaria de diversos establecimientos y servicios públicos. Sobre las aguas de abastecimiento refiere que «... tres son las conducciones, conocidas con los nombres de Potables, principal y San Isidro. La primera llega por tubería de hierro asfaltado hasta un depósito de unos seiscientos metros cúbicos de

46 MuÑoz MaCHAdO, S. (1995), pp. 50-52

47 Artículo 30 de la Instrucción de 12/1/1904.

48 BÉCARES, F. (1935), pp. 3-8.

49 AHMY, AC SO 17/10/1910. 
capacidad y del que nuevamente entubada sale a distribuirse por edificios de la población y fuentes públicas. Las otras dos sirven casi exclusivamente para riegos y la principal es la que suministra caudal para los lavaderos antes de los que existe la fábrica de aceite que algunas veces impurifica el agua lo mismo que la de vinos y alcoholes situada después de aquellos y corriente abajo las residuales de otra nave para el degüello de reses de cerda». Los informes sobre la plaza de abastos, el asilo de ancianos y hospital anejo, y el cementerio, son favorables y, sobre la cárcel, que se encuentra situada «... en sitio céntrico, en los bajos del Ayuntamiento, local de muy escasa capacidad, luz y ventilación y con gran humedad por lo que no reune en absoluto las condiciones que debería».

Sin embargo, a pesar del infonne oficial, la realidad es que las prácticas antihigiénicas eran frecuentes y muchas de ellas eran denunciadas por la prensa de la época ${ }^{50}$. Las denuncias se refieren fundamentalmente a la limpieza pública; se habla de callejones inmundos, ausencia de sumideros en las casas, ausencia de alcantarillado, presencia de animales muertos y excrementos en las calles, y existencia en las casas particulares de «... basureros y cuadras bajo la escalera que da acceso a las habitaciones» ${ }^{51}$

En 1913 el Ayuntamiento decide colocar unos urinarios públicos, que fueron clausurados poco tiempo después ante el clamor público de ineficacia y de constituir nuevos focos de infección ${ }^{52}$.

A partir de 1916, las denuncias del concejal socialista Sebastián Pérez en el Ayuntamiento son constantes en torno a tres cuestiones fundamentales. En primer lugar, el problema de las aguas residuales que los vecinos arrojan a las calles al no disponer de sumideros ni retretes, planteándose por primera vez la necesidad del alcantarillado público. En algunas zonas, como las calles de San Juan, Santa Bárbara y Jumilla, la construcción de sumideros o pozos negros en los domicilios era dificultosa por las condiciones de dureza e impermeabilidad del terreno. En segundo lugar la limpieza de las calles y fundamentalmente la existencia de enormes cantidades de tierra en las mismas, sobre todo en las épocas de sequía y su conversión en lodazales tras la lluvia. Por último, las denuncias de Sebastián Pérez se referían a la adultera-

50 Denuncia sobre higiene pública aparecida en La Tertulia de 13 de agosto de 1911: «Señor alcalde: ¿Puede decirnos si se han habilitado para urinarios públicos y receptores de excrementos las calles de San Felipe, Peligros, Gerona, Arco, Murillo, Aduana, Don Lucio y una porción mas, donde la vista y el olfato del transeunte se ven desagradablemente sorprendidos por cosas y olores nada buenos?...»

51 Juventud, 7/11/1914.

52 En esa época circuló en Yecla la siguiente coplilla:

"Que hagan la sustitución

rogamos por caridad

de los focos de infección

por los de electricidad»

La Peña, 26/7/1913. 
ción sistemática de alimentos, sobre todo del pan y la leche, y la venta de carnes en domicilios particulares sin el control veterinario adecuado.

En cuanto al abastecimiento de agua, la situación había mejorado ostensiblemente. Las primeras fuentes públicas se habían instalado en la plaza del Colegio, San Isidro, Quevedo e Iglesia Vieja. El problema era la falta de presión suficiente, por lo que el suministro era escaso, decidiéndose trasladarlas a zonas más bajas en marzo de 1905. De todas formas, para el consumo familiar de la mayor parte de la población se impuso el sistema de los «aguadores». En 1905, se coloca una bomba para la extracción de agua del Heredamiento Principal y utilizarla como potable. El agua se tomaba «... por tubería del Heredamiento del Agua Principal y sitio denominado el Puente y (se conducirá) al lugar conocido con el nombre de la voquera» ${ }^{53}$. Los aguadores cargaban obligatoriamente el agua en dicho lugar y la pagaban a diez céntimos de peseta por cada cuba o tonel. El pago se realizaba a la empresa explotadora en concepto de alquiler de la bomba, ya que el agua era propiedad del Ayuntamiento. Tenían expresamente prohibido llevar los toneles de otra forma para asegurar que el agua de consumo público tuviera las mejores condiciones de potabilidad y no circulase, en ningún momento, en conducción abierta.

La crisis de subsistencia de la segunda década del siglo, especialmente a partir de 1915, contribuyó indudablemente al empeoramiento de las condiciones sanitarias de la población. El trigo y la harina desaparecieron del mercado y sus precios se elevaron de forma alarmante, la usura se generalizó y los intereses cobrados se elevaron hasta al 500\%, anual. Las denuncias de la prensa, sobre todo del periódico Juventud, hablan de sueldos estancados, emigración de braceros y una situación social desesperada: «... niños harapientos y mujeres escuálidas nos persiguen a cada momento demandando un trozo de pan con voz lastimera... por nuestras puertas desfila una constante procesión de mendigos que nos ponen en un nervioso malestar que aumenta y crece por momentos y que amenaza ahogarnos» ${ }^{54}$. De hecho, en el reemplazo de 1915, el porcentaje de mozos «inútiles» en Yecla llegó al 40\%, lo que es interpretado por el referido periódico como consecuencia de «... la degeneración que engendra la insuficiencia de los alimentos».

Las protestas de las organizaciones obreras como las «Asociaciones Obreras Agrícolas», «Albañiles» y de la «Juventud Socialista», se suceden en manifestaciones y escritos presentados en el Ayuntamiento, solicitando la urbanización y arreglo de calles, el abaratamiento de las subsistencias, la sustitución del impuesto de consumos y el repeso diario del pan y análisis de sus componentes ${ }^{55}$, estableciéndose una Junta de Subsistencias formada por siete concejales, «... para que entiendan en todos los asuntos relacionados con los artículos de primera necesidad».

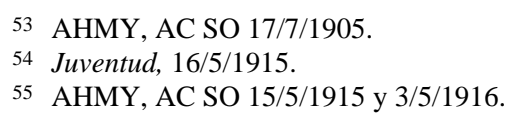


Finalmente, en la década de los años veinte, el Ayuntamiento decide establecer un servicio para la limpieza e higiene pública de las calles. Para ello se acuerda comprar un camión y se decide reservar la décima parte de la contribución urbana para la limpieza pública ${ }^{56}$.

Asimismo, en estos años, se decide acometer el estudio de los dos proyectos que serían esenciales en la mejora definitiva de las condiciones higiénicas de la población: el servicio de basuras y el establecimiento de la red pública de aguas potables y la construcción del alcantarillado público. En la instauración de ambos servicios se intentó adelantar la iniciativa privada. En el caso de la recogida de basuras, a instancias de la oposición en el Ayuntamiento, se aprobó la creación de un Servicio Municipal de Basuras en 1926, en contra de la opinión del alcalde Portillo, que pretendía arrendarlo a un particular ${ }^{57}$. Por otro lado, la red de aguas potables estuvo inicialmente en manos privadas ${ }^{58}$, hasta que en 1927 aparece en la prensa local una descripción detallada de los proyectos de alcantarillado y abastecimiento de aguas, realizados por los arquitectos Massot y Barenys, a instancias de la alcaldía de D. José del Portillo ${ }^{59}$.

El presupuesto extraordinario para las obras de «ELEVACIÓN DEL DEPÓSITO, ABASTECIMIENTO DE AGUAS Y ALCANTARILLADO», es aprobado en la sesión de 25 de enero de 1928, publicándose la subasta pública en la Gaceta de 18 de agosto de 1928. La inauguración de las obras tuvo lugar el 28 de octubre de dicho año. Sin embargo, hasta el final del período que consideramos, los pozos negros y el abastecimiento de aguas por medio de aguadores, fueron la norma para la mayor parte de la población de Yecla.

En cuanto a la organización sanitaria municipal propiamente dicha, durante las primeras décadas del siglo, estuvo constituida fundamentalmente por la asistencia a los pobres por distritos médicos, los titulares de farmacia y de veterinaria. La Junta de Sanidad, aunque teóricarnente sigue existiendo, apenas se reúne, salvo en contadas ocasiones, como en 1910, ante la amenaza de una nueva epidemia de cólera ${ }^{60}$.

\footnotetext{
56 AHMY, AC SO 23/3/1923.

57 AHMY, AC SO 1/11/1926.

58 En la sesión de 3/11/1899 se había hecho la concesión de dicha red a empresarios privados y en la década de los veinte estaba en manos de D. Bartolomé Maestre Ortega «... para la traída, distribución y explotación de dichas aguas». Este empresario protestó ante el Ayuntamiento por considerar «... lesivos a sus intereses los trabajos practicados por las calles de esta población para la construcción de su alcantarillado puesto que con los mismos se ha destrozado y dejado inservible la red de tuberías y acometidas que para el suministro del servicio de aguas potables se hallaba establecido en virtud de la concesión del propio Ayuntamiento» (AHMY, AC SO 17/9/1929).

59 AHMY, libro 2.095, «Dos magnos proyectos de urbanización», Adelante, 5 de noviembre de 1927.

60 Una de las últimas actas de la Junta de Sanidad de Yecla que hemos podido consultar se refiere a la creación de comisiones para la visita de domicilios y edificios públicos para verificar su estado de salubridad e higiene, ante la amenaza colérica: «para conjurar en lo posible el peligro de que invada a esta población». En las visitas que se practicaron se encontraron las siguientes deficiencias: Segundo distrito, arreglar un retrete dándole mayor capacidad y ventilación, extraer basura de un domicilio y
} 
El número de titulares de veterinaria fue incrementado, de uno a tres, en 1914, «... teniendo en cuenta el excesivo número de habitantes y ser insuficiente una nueva plaza» ${ }^{61}$. Asimismo, al final del período considerado, el Ayuntamiento estableció los servicios de practicante y matronas municipales, así como la contratación de un tocólogo municipal en 1930.

Los listados de familias pobres eran elaborados por la Comisión Municipal de Beneficencia y Sanidad y entregados a los médicos y farmacéuticos titulares para la asistencia médica y el suministro gratuito de medicamentos. Como es natural, el mayor número de familias incluidas en los listados corresponde a los barrios de las cuevas y a las calles más humildes ${ }^{62}$.

Por otro lado, la actividad sanitaria municipal durante estas décadas consistió fundamentalmente en la adopción de medidas profilácticas contra enfermedades concretas a medida que se producían «alertas» por la aparición de algunos casos. A las medidas contra la triquinosis y la rabia de principios de siglo le seguirán acciones contra algunos focos de lepra en las calles de Cura Ibáñez y Cerro ${ }^{63}$. La amenaza del cólera de 1910 y la presencia constante de tuberculosis, sarampión y viruela entre otras enfermedades infecciosas, hace que las cuestiones sanitarias sean objeto de discusión pública e incluso de atención preferente de la prensa local, en ocasiones con defensas elogiosas de las actuaciones sanitarias municipales y, en otras, con críticas sobre la precaria situación sanitaria de la población, dependiendo de la tendencia del periódico con respecto al gobierno municipal ${ }^{64}$.

construir un retrete, construir un retrete sumidor, limpieza de un patio. Tercer distrito: ventilar un retrete y construir sifones con cierre hidráulico, impedir el lavado de ropas en un patio sin antes limpiar éste y la cochera y arreglar la boca de entrada del sumidor, ventilar un retrete y colocar sifón hidráulico (AHMY, leg. 479).

61 AHMY, leg. 288. En realidad, la necesidad del aumento de plazas de veterinario titular era consecuencia del incremento de las funciones de policía bromatológica en mercados y mataderos que la Instrucción General encargaba a los servicios municipales de veterinaria (Inspectores de carnes y alimentos). Dichas funciones serían reguladas posteriormente en la Bases para la redacción de los Reglamentos de Higiene de 1910 y que en 1925 se convertirían en el Reglamento de Sanidad Municipal (Cf. MUÑOZ MACHADO, S., op. cit., 58-70).

62 En 1905 figuran en el listado de pobres 734 familias y en 1909 sólo 305 familias. Las variaciones dependen del criterio más o menos restrictivo de la Comisión para la inclusión en los listados, según las disponibilidades presupuestarias (AHMY, leg. 501).

63 AHMY, AC SO 19/7/1909. En esta sesión se da cuenta del despido de algún enfermo de lepra ingresado en el hospital de Elda y enviados a sus domicilios en Yecla, por lo que se entablan gestiones para su ingreso en el hospital de Gandía.

64 El periódico Juventud suele ser el más crítico con la situación sanitaria. En su edición del 12 de diciembre de 1915, y en un artículo titulado «La salud pública», se denuncia el tremendo incremento que está alcanzando la difusión de la tuberculosis y otras enfermedades debido a «... la terrible promiscuidad en que se hallan las ropas en los lavaderos públicos, el agua donde se han lavado unas ropas sirve para lavar otras». Se solicita, asimismo, que los médicos den parte diario al Ayuntamiento de los enfermos 
La desinfección de locales públicos y casas de enfermos es una actividad frecuente de los servicios municipales, para lo que se adquirieron en 1911 los correspondientes aparatos, según tenemos noticia a través del periódico La tertulia de 6 de agosto de $1911^{65}$. En cuanto a los programas de vacunación contra la viruela, es una de las actividades más constantes, ya que tenemos noticias de vacunaciones desde, al menos, $1866^{66}$.

Quizá la epidemia de gripe de 1918, que describiremos en otro lugar, fue la última ocasión en que los servicios sanitarios municipales hubieron de emplearse a fondo, debido a la magnitud de la catástrofe pública y a las estrictas medidas emanadas del Gobierno Civil.

atendidos y el diagnóstico de los mismos, y se denuncia lo mal acondicionadas que están muchas casas, sobre todo las de los obreros «... por ser reducidas, estar poco ventiladas y carecer de retretes».

65 En una entrevista al alcalde, éste da cuenta de la adquisición de un Pulverizador (Automax) de 22 litros, un aparato Torrens para gasificar formol, un barril de cloruro y tres kilos de tabletas de formalina.

66 A partir de 1866 aparece en los motes de defunción de párvulos de la iglesia del Niño el dato sobre la vacunación o no del fallecido. Asimismo, disponemos de estadísticas de vacunados en el último cuarto del siglo XIX y, por supuesto, en el XX. 